\title{
Pandemic Balancing Acts: Early COVID-19 lockdown changes how Germans trade off lives and weigh constitutional powers*
}

\author{
Markus Tepe \\ University of Oldenburg \\ markus.tepe@uol.de \\ Michael Jankowski \\ University of Oldenburg \\ michael.jankowski@uol.de
}

\author{
Pieter Vanhuysee \\ University of Southern Denmark \\ vanhuysse@sam.sdu.dk \\ Christina-Marie Juen \\ University of Oldenburg \\ christina-marie.juen@uol.de
}

\author{
Florian Erlbruch \\ University of Oldenburg \\ florian.erlbruch@uol.de
}

\begin{abstract}
Has the COVID-19 pandemic caused early shifts in how citizens view constitutional power balances and policy tradeoffs? We conducted two survey experiments among 1192 Germans during the first week of lockdown. In a priming experiment, subjects were cued to think about the COVID-19 lockdown. While not affecting their 'federal vs. state' power balance preferences, this increased support for shifting power from parliaments toward governments. In a framing experiment, we traded a maximalist imperative for the state to take all measures to minimize casualties against long-term losses in economic wealth or civic freedoms. Support for this maximalist policy was somewhat lower when traded against freedom losses, but was unchanged among the youngest and oldest respondents. Support was substantially lower when traded against economic losses, especially among young respondents. These results document significant initial switches in mass preferences about democratic governance caused by the pandemic. They may also signal looming generational tensions.
\end{abstract}

Keywords: COVID-19 $\cdot$ lockdown $\cdot$ tradeoffs $\cdot$ survey experiments $\cdot$ policy preferences $\cdot$ constitutional federalism

\footnotetext{
${ }^{*}$ Replication material will be made publicly available at the Harvard Dataverse before publication.
} 
Early measures taken in the first months of 2020 by democratic governments to combat the COVID-19 pandemic have almost invariably included strong limits on citizens' freedom of movement and of assembly, and often extensive economic measures to support firms and workers, and in some cases to increase state control over key sectors of the economy (Elgin, Basbug and Yalaman, 2020). These developments illustrate the potential of the COVID-19 pandemic to uproot the existing status quo in terms of democratic governance. And they explain why many fear a turn toward authoritarianism and a weakening of liberal democracy.

Extraordinary population health crises that endanger human lives on a large scale have often upended the constitutional balance of power in democracies by widening the reach of the state and strengthening the power of the executive (Obinger, Petersen and Starke, 2018; Snowden, 2019). Crises require fast and decisive measures; the executive branch of government is typically seen as more effective in such contexts than the legislative branch (Owens and Pelizzo, 2009). Constitutional rights and liberties are then often framed by politicians as a cost worth bearing for the sake of security or health (Baker, 2003).

But how might citizens view these essential questions of democratic governance today, given the scale, speed, and salience of the COVID-19 pandemic and the severity and economic implications of the lockdown measures? In times of major crisis, popular opinion often 'rallies round the flag,' and favors strong leaders perceived to take tough policy measures (Mueller, 1970; Bol et al., 2020). Voters do not always reject unilateral executive powers, especially when these further their partisan and policy preferences (Christenson and Kriner, 2017; Hetherington and Suhay, 2011), and they often reward politicians who implement beneficial policies in crisis times (Bechtel and Hainmueller, 2011). When citizens are (made to) feel anxious or threatened, they tend to have higher support for restrictions on the rights of others, to seek out threatening information (even when wrong) and to be more likely to agree with that information. They also seek out political actors who propose fast and simple solutions (Albertson and Gadarian, 2015).

The COVID-19 pandemic is a classic example of such a major anxiety-inducing crisis. It directly affects the protection of two nearly universally valued goods (good health and life), which is clearly best achieved primarily through collective, rather than merely private, action. In order to enable speedy and effective population health measures, citizens may therefore be 
willing to pay a high cost in terms of other valued goods, and/or to upend reigning democratic power balances by giving central governments more power (Fetzer et al., 2020). The fast-rising human cost of COVID-19 has quickly led to demands for governments to do all they can to save human lives. But equally, salient questions have arisen about the cost of protection in terms of both economic consequences (e.g. the economic slowdown or slump caused by lengthy shutdowns) and freedom (e.g. does the pandemic necessitate a stronger power for the executive branch of government?). Early results for Spain indicate that the COVID-19 pandemic has led to a larger popular demand for strong leadership, a greater willingness to give up individual freedoms, and a sharp increase in support for technocratic governance (Amat et al., 2020). Crossnational opinion polls suggest that citizens are generally more supportive of their government in times of the COVID-19 pandemic (Bol et al., 2020). But opinion polls rely on observational data.

This study experimentally enquires into the causal effects of the COVID-19 crisis on citizens preferences regarding democratic governance. We ask how citizens living under newly implemented COVID-19 lockdown conditions perform two balancing acts, or solve two democratic dilemmas, that are essential to the functioning of any democracy. First, the 'democratic power balances' dilemma. Has the COVID-19 lockdown led citizens to favor more power for the executive branch of government at the expense of the legislative branch, and for the national level of a federal government at the expense of the local (states) level? Second, the 'saving lives at which cost' dilemma. How do citizens weigh the population health imperative to take all measures possible to minimize pandemic casualties against two types of long-term cost such a maximalist policy approach may carry - in terms of macro-economic wealth losses and civil liberties losses? In other words, we study the politics of the pandemic in terms of both constitutional power balances and policy tradeoffs.

\section{Two Survey Experiments on COVID-19 in Germany}

We report results from two survey experiments conducted among a sample of 1192 respondents in Germany. The COVID-19 lockdown in Germany was implemented in two steps. On 16 March 2020, the states ('Länder') ordered the closure of schools, daycare centers and public cultural 
facilities (theatres, museums, sports events) and banned major public events. Harsher restrictions followed on 22 March 2020, when federal government and states agreed on social distancing orders permitting presence in public spaces only when alone, with one other person, or with one's household members. This lockdown immediately changed the daily lives of Germans. This study's survey experiment started on 26 March, when all respondents had at least three days of lived lockdown experience behind them. It ended on 1 April 2020. While the sample is not fully representative of the German population, it is balanced in terms of age, gender, and political orientation, and among conditions within the same experiment (a full description of the sample can be found in SI Method). The survey started with several questions regarding respondents' political attitudes, such as their placement on the left-right scale. After these questions the priming experiment was conducted. After the priming we asked respondents several questions regarding their socio-demographic characteristics. Finally, the survey ended with the framing experiment. The design of both experiments will be discussed along with the results.

\section{Experiment 1: COVID-19 and Democratic Power Balances}

The effect of the COVID-19 pandemic on democratic power balances is analyzed by means of a priming experiment using open response questions as treatments. Respondents were randomly assigned to one of the following three experimental conditions. Respondents in the control condition did not get open response questions. A second group received the COVID-19 priming treatment which reminded subjects of the recent lockdown measures. The treatment then went on to ask respondents two open response questions about which situation they felt personally particularly restricted in by these measures, and whether they could also see a positive side to the measures to reduce social contacts. Since the lockdown in its early days could be very salient even in the minds of those who did not get the COVID-19 priming treatment, a third group of respondents received a treatment that focused on the German constitution. Here we reminded subjects that the constitution contains rules on how a state is structured and who can pass laws, and that it had just turned seventy. We then again asked subjects two open response questions, about what they appreciate about the constitution and whether there are any changes respondents would like to see to it. Then all three groups received the same two outcome questions. 
Like the United States, Germany has a unitary political culture but also with constitutionally delineated competences for the federal and 'state' levels (Scharpf, 2008). Especially in federal states such as Germany, there are at least two potential implications of COVID-19 on constitutional power balance preferences. On the one hand, the crisis may cause citizens to want to consolidate power at the executive rather than the legislative branch of government. On the other, the crisis may cause citizens to want to concentrate political power at the federal rather than the state level. We use this two-dimensional constitutional space (Scharpf, 2008) to experimentally inquire about citizens' evolving views of the balance of powers within German federal governance. Thus, our outcome questions measure respondents' willingness to shift political power from the states to the federal level and from parliament to government. Both questions are measured on a slider ranging from 0 to 100 , where the value of 50 was preselected and represents the 'status quo'. With regard to the power balance between the government and parliament, values closer to 0 indicate more power for the government and values closer to 100 indicate a preference for more power for the parliament. In the questions regarding the balance of power between the federal government and the state governments a value closer to 0 indicates more power for the federal level and a value closer to 100 indicates a preference for more power for the states.

Figure 1 shows the predicted values of the three treatments (No Prime, COVID-19 Prime and Constitutional Prime) on the two questions. The constitutional priming treatment had no effect on either dimension compared to the control group which received no specific prime. The COVID-19 priming treatment also had no effect on subjects' willingness to shift power from the state to the federal level, but it caused respondents to be more willing to shift power away from parliaments toward governments. We also studied whether these priming effects are conditioned by the respondent's own age (18-69) or by the share of infected inhabitants in the local district (Landkreis; equivalent to county) in which the respondent lives, as measured on the day before the respondent participated in the survey. Age is considered to approximate respondents' risk of dying from COVID-19, as current evidence from epidemiology indicates that COVID-19 mortality rate increases exponentially with age. The share of people infected in respondents' local district in turn approximates the risk of getting infected. Both these measures are useful 
proxies at best, since COVID-19 mortality risk is also dependent on pre-existing conditions and exposure risks such as work in the health care sector. Interestingly, neither of these proxy risk variables conditioned the treatment effect reported in Figure 1 (Figures S3-S6 in the SI).

Figure 1: Priming Experiment (Federal vs State level and Government vs Parliament power)

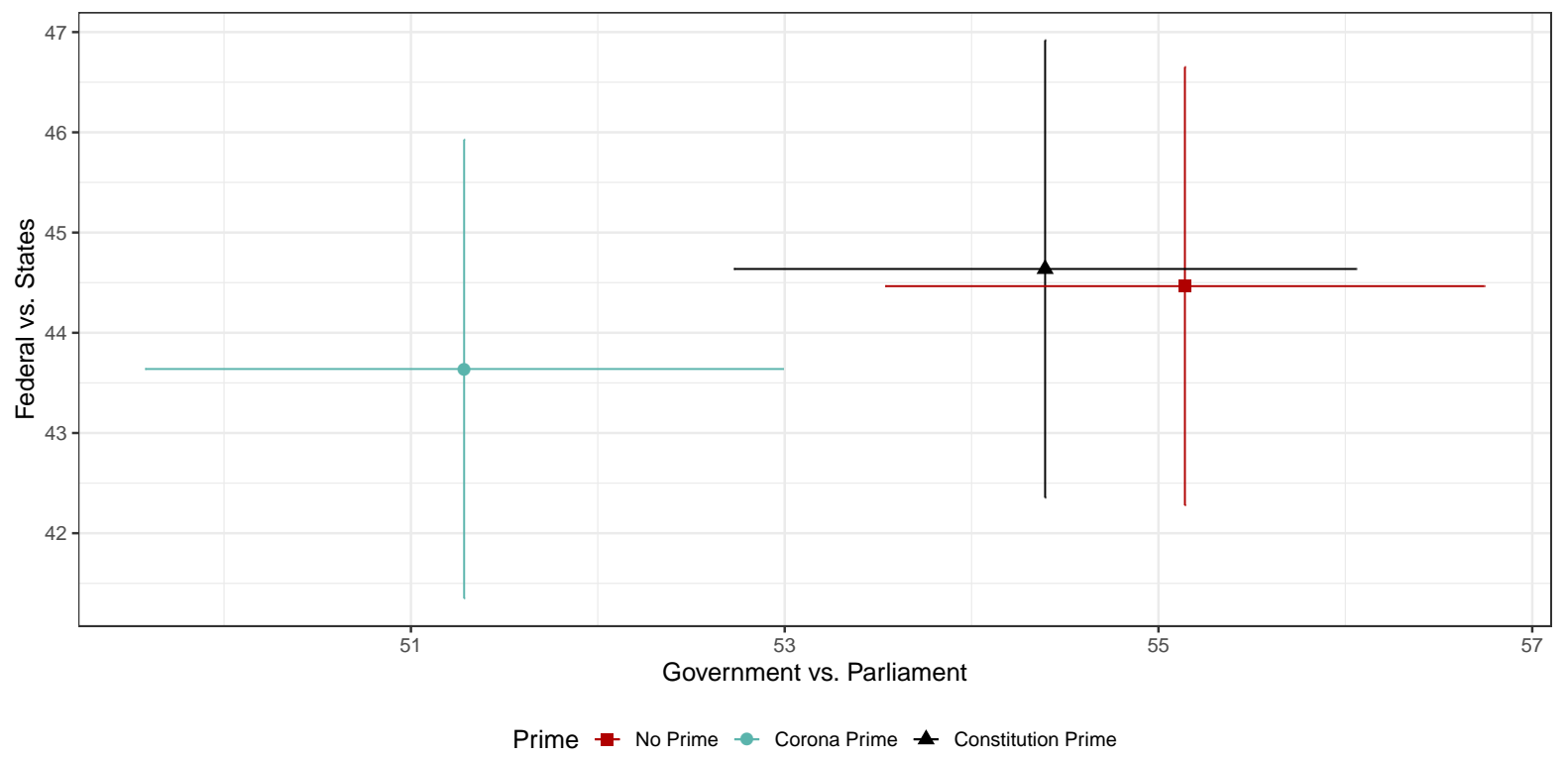

Note: Results of priming experiment on democratic governance (pooled $n=1,192$ ) for three priming conditions. 'No Prime' identifies respondents who received no priming questions ( $\mathrm{n}=389)$. 'Corona Prime' and 'Constitution Prime' identify respondents who had to answer two open-response survey questions regarding, respectively, the COVID-19 pandemic $(n=404)$. and the German constitution $(n=399)$, before then answering the questions regarding democratic governance. For each treatment condition, predicted values on the response scale are displayed. Horizontal and vertical lines denote $95 \%$ confidence intervals.

\section{Experiment 2: COVID-19 and Policy Tradeoff Preferences}

Catastrophic events and/or major crises in population health and safety, as well as their economic costs and consequences, can be expected to shift the landscape of political and policy preferences. Personal health risks (Pacheco and Fletcher, 2015) and a higher mortality salience (Burke, Kosloff and Landau, 2013) can both be expected to be salient drivers of political behavior. Personal economic shocks such as job loss or sharp income drops can increase political support for a more expansive welfare state, but also decrease trust in political institutions (Margalit, 2019). Therefore, this study's second experiment is a framing study of policy tradeoff preferences. We test Germans' willingness to pay a price for a maximalist human life protection approach in response to COVID-19. We ask subjects in the control group how much they agree with the statement that 'the state must take all measures to minimize the number of deaths caused by 
the novel coronavirus.' The two treatment groups get the same question, but with an additional caveat: respectively 'even if these measures lead to a long-term loss of economic wealth caused by insolvencies, unemployment and public debt' (economy frame), and 'even if these measures lead to long-term restriction of civil liberties (e.g. freedom of assembly and movement)' (freedom frame). For all three questions the same 11-point response scale is used where the value 1 represents 'complete disagreement' with the given statement and the value 11 represents 'complete agreement' with the given statement.

Figure $2 \mathrm{a}$ shows the predicted values of the framing treatment on subjects' responses regarding whether the state must take all measures to minimize casualties. In the baseline treatment (no tradeoff frame), the mean response is high, at 9.51. This goes down to 7.84 in the economy frame and 8.99 in the freedom frame. Both treatments cause a significant reduction in support of the maximalist policy approach to saving lives, as can be seen from the marginal effects presented in Figure $2 b$. Mentally activating either the macro-economic or the freedom costs of the lockdown reduced support in both cases, although the negative effect is substantially larger (about 1.6) for the economic loss cue.

Figure 2: Results of the Framing Experiment
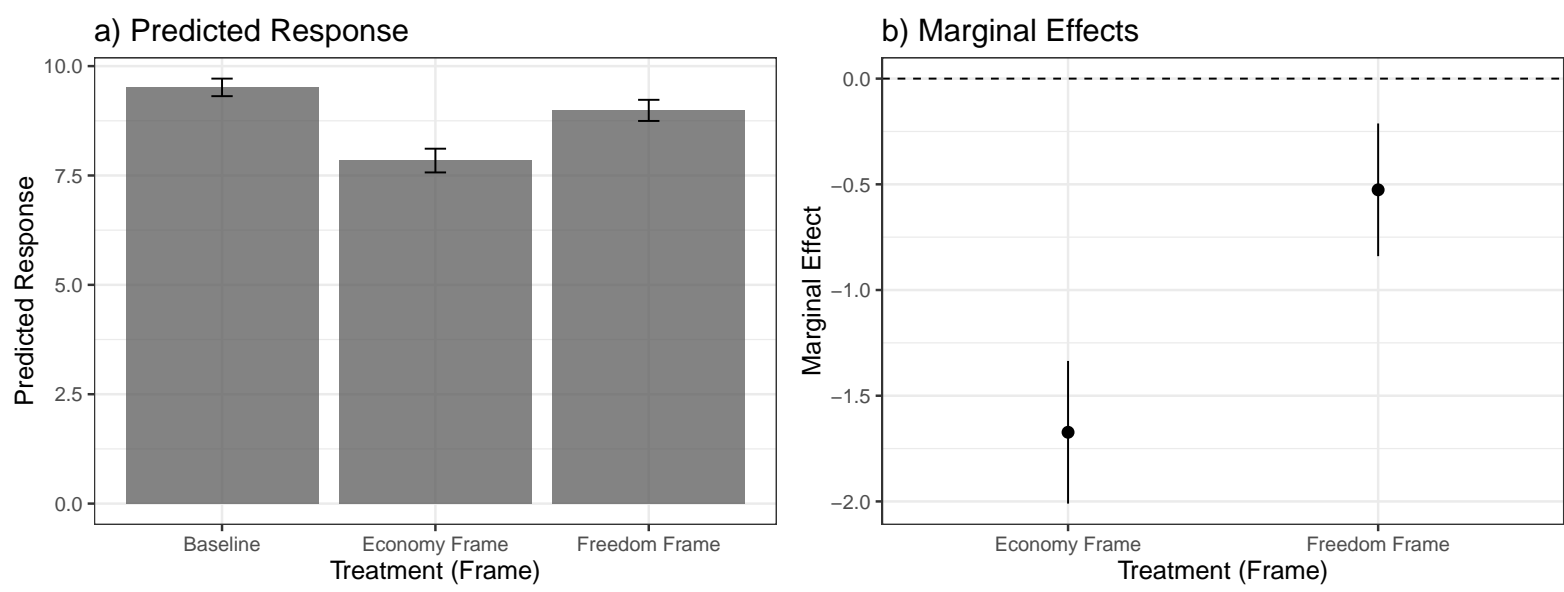

Note: Results of framing experiment on support to the statement 'the state must take all measures to minimize the number of deaths caused by the novel coronavirus' (pooled $n=1,192)$. Response scale ranges from 1 (= 'totally disagree') to 11 (= 'totally agree'). 'Baseline' refers to the treatment condition without a frame $(n=405)$. 'Economy frame' and 'Freedom frame' refer to the treatments in which negative consequences for, respectively, the economy $(n=383)$ and civil liberties $(n=404)$ are mentioned. a) Predicted values on the response scale for each treatment condition. Whiskers are $95 \%$ confidence intervals. b) Average marginal effects of 'economy frame' and 'freedom frame' with respect to 'baseline' condition. Vertical lines are $95 \%$ confidence intervals. 
Figure 3 further demonstrates how the framing effects are conditioned by two proxy variables for mortality risk (respondent's own age) and infection risk (share of infected inhabitants in respondent's local district of residence). The Figures $3 \mathrm{a} / \mathrm{c}$ shows the conditional effect of age. As Figure 3a indicates, the negative effect of the economy frame is conditioned by age. This negative effect is particularly strong among those aged 18-25. The negative effect becomes weaker among respondents in their thirties and becomes somewhat larger again among those in their forties and fifties. But it becomes statistically insignificant only among those aged above 65 . In other words, whereas middle-aged, and even more so, younger Germans strongly reduce their support for a maximalist casualty prevention policy when this comes at the cost of long-term macro-economic losses, such losses do not affect support among Germans after retirement age. The conditional effect of age for the freedom frame looks very different (bottom left panel). Among the youngest and the oldest in our sample, long-term restrictions of civil liberties do not affect support for the maximalist health approach at all. Only among those aged in their late thirties to early sixties does the loss of civic freedoms frame reduce support for the maximalist approach. Compared to the economy frame, however, these marginal effects are much smaller.

Figure $3 b / d$ in turn shows that neither the economy frame (Figure $3 b$ ) nor the freedom frame (Figure 3d) is conditioned by the share of COVID-19 infections in the respondent's own local district (ln). Additional analyses further show that respondents' self-reported ideological orientation on a left-right scale does not significantly moderate these tradeoff preferences either (Figure S7a/b in the SI) (Kushner Gadarian, Goodman and Pepinsky, 2020). Because our framing experiment was conducted after the priming experiment on the same set of respondents, there was the possibility that the priming treatments might either affect the framing experiment outcome directly or moderate the effect of the framing experiment treatments. We have tested whether this is the case, but found no evidence that the priming treatments had an effect on the framing tradeoff questions or that the framing treatments were moderated by the priming treatments (see Table S5 in the SI). 
Figure 3: Results of the Framing Experiment Conditioned by Age and Infected

a) Interaction: Age \& Economy Frame

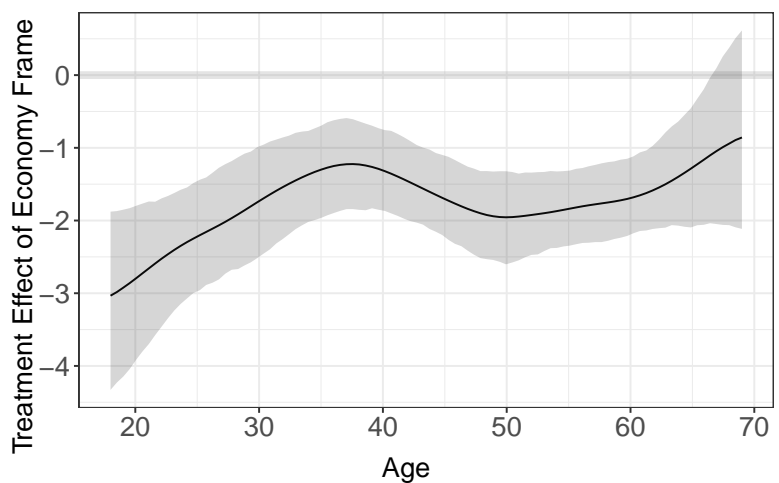

c) Interaction: Age \& Freedom Frame

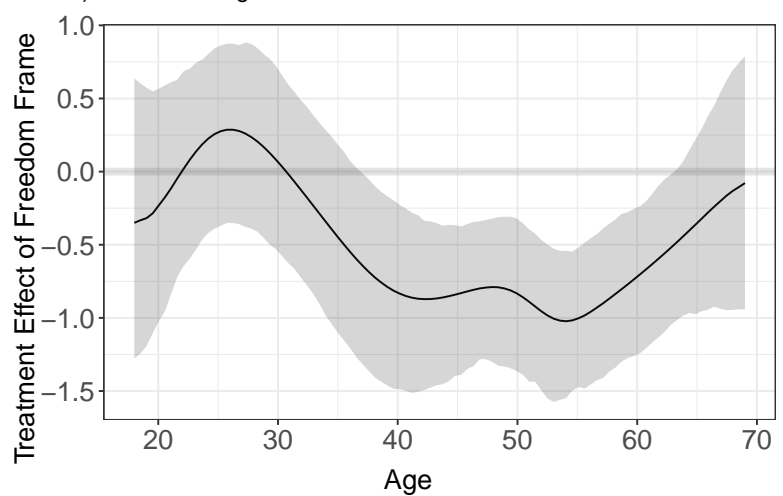

b) Interaction: Infected \& Economy Frame

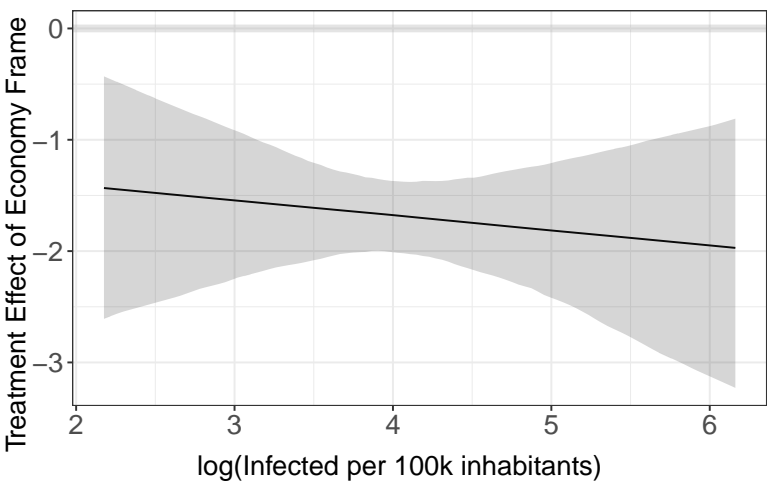

d) Interaction: Infected \& Freedom Frame

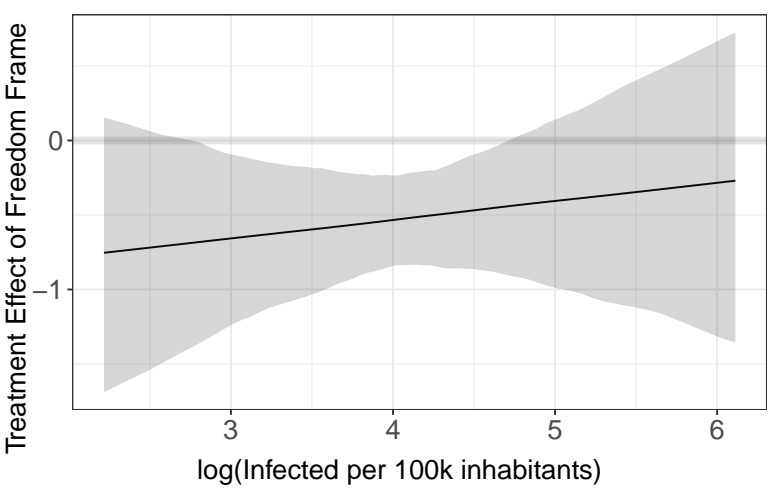

Note: Effect of the economy and freedom frame treatment in the framing experiment conditional on respondents' risk due to COVID-19. a) and c) Interaction effect between economy or freedom frame and the age of respondent. $b$ and d) Interaction effect between economy or freedom frame and the logged number of infected inhabitants in a respondent's local district (Landkreis) per 100,000 inhabitants. Interaction effects are estimated using the 'kernel'-estimator as described in Hainmueller, Mummolo and Xu (2019). Shaded areas are 95\% confidence intervals based on 500 bootstrap iterations.

\section{Conclusions}

Our results suggest that the COVID-19 pandemic's early lockdown conditions have significantly shifted the way Germans think about both the price of maximum casualty prevention and the constitutional balance of power between the executive and legislative branches of government. Although being primed to think about the COVID-19 lockdown has no effect on preferences regarding the 'federal vs. state' power balance, it does make citizens more willing to shift power away from parliaments toward governments at both levels. And once the maximalist imperative for the state to take all measures to minimize casualties is traded off against long-term economic or freedom losses, general support for this approach goes down. Support for the maximalist life-saving approach is somewhat lower in the freedom frame, but this effect is entirely driven 
by middle-aged respondents. Support is substantially lower in the economy frame among all respondents up to age 67; most so among respondents aged 18 to 30.

In other words, Germans would like to give more power to the executive branch of government. And they would rather pay for maximum state protection against COVID-19 casualties with long-term losses of civil liberties than with long-term macro-economic wealth losses. While not justifying fears for a weakening of democratic governance as such, our results do show significant initial switches in mass political preferences caused by the pandemic. They indicate that Germans' commitment to the existing democratic order is highly contingent on other concerns and that this large-scale pandemic can induce a substantial willingness to give up freedom for casualty prevention and to change parts of the existing constitutional balance of powers. Our results also indicate looming generational tensions. In the near future, young people may well start protesting more strongly against further extensions and further economic costs of the lockdown.

\section{References}

Albertson, Bethany and Shana K. Gadarian. 2015. Anxious Politics: Democratic Politics in a Threatening World. Cambridge: Cambridge University Press.

Amat, Francesc, Andreu Arenas, Albert Falcó-Gimeno and Jordi Muñoz. 2020. Pandemics meet democracy. Experimental evidence from the COVID-19 crisis in Spain. preprint SocArXiv. URL: https://osf.io/dkusw

Baker, Nancy V. 2003. “National Security versus Civil Liberties.” Presidential Studies Quarterly 33(3):547-567.

Bechtel, Michael M. and Jens Hainmueller. 2011. "How Lasting Is Voter Gratitude? An Analysis of the Short- and Long-Term Electoral Returns to Beneficial Policy.” American Journal of Political Science 55(4):852-868.

Bol, Damien, Marco Giani, André Blais and Peter John Loewen. 2020. "The effect of COVID-19 lockdowns on political support: Some good news for democracy?" European Journal of Political Research . (Forthcoming). Preprint: https://osf.io/7hpj9.

Burke, Brian L., Spee Kosloff and Mark J. Landau. 2013. "Death Goes to the Polls: A MetaAnalysis of Mortality Salience Effects on Political Attitudes.” Political Psychology 34(2):183200. 
Christenson, Dino P. and Douglas L. Kriner. 2017. "Constitutional Qualms or Politics as Usual? The Factors Shaping Public Support for Unilateral Action.” American Journal of Political Science 61(2):335-349.

Elgin, Ceyhun, Gokce Basbug and Abdullah Yalaman. 2020. "Economic policy responses to a pandemic: Developing the Covid-19 economic stimulus index." Covid Economics: Vetted and Real-Time Papers 1(3):40-53.

Fetzer, Thiemo, Lukas Hensel, Johannes Hermle and Christopher Roth. 2020. "Coronavirus Perceptions And Economic Anxiety." arXiv:2003.03848 [econ, q-fin] .

URL: http://arxiv.org/abs/2003.03848

Hainmueller, Jens, Jonathan Mummolo and Yiqing Xu. 2019. "How Much Should We Trust Estimates from Multiplicative Interaction Models? Simple Tools to Improve Empirical Practice." Political Analysis 27(2):163-192.

Hetherington, Marc J. and Elizabeth Suhay. 2011. “Authoritarianism, Threat, and Americans' Support for the War on Terror.” American Journal of Political Science 55(3):546-560.

Kushner Gadarian, Shana, Sara Wallace Goodman and Thomas B. Pepinsky. 2020. "Partisanship, Health Behavior, and Policy Attitudes in the Early Stages of the COVID-19 Pandemic.".

URL: https://papers. ssrn.com/abstract $=3562796$

Margalit, Yotam. 2019. "Political Responses to Economic Shocks." Annual Review of Political Science 22(1):277-295.

Mueller, John E. 1970. "Presidential Popularity from Truman to Johnson.” American Political Science Review 64(1):18-34.

Obinger, Herbert, Klaus Petersen and Peter Starke. 2018. Warfare and Welfare. Oxford, New York: Oxford University Press.

Owens, John E. and Riccardo Pelizzo. 2009. "Introduction: The Impact of the War on Terror on Executive-Legislative Relations: A Global Perspective.” The Journal of Legislative Studies 15(2-3):119-146.

Pacheco, Julianna and Jason Fletcher. 2015. "Incorporating Health into Studies of Political Behavior: Evidence for Turnout and Partisanship.” Political Research Quarterly 68(1):104116.

Scharpf, Fritz W. 2008. "Community, Diversity and Autonomy: The Challenges of Reforming German Federalism.” German Politics 17(4):509-521.

Snowden, Frank. 2019. Epidemics and Society. New Haven and London: Yale University Press. 


\section{Supplementary Material for "COVID-19 changes how citizens trade off lives and weigh democratic power balances"}

\section{Description of Sample and Experiment}

Sample. We surveyed 1300 eligible voters in Germany (see Supplementary Information for details). The international survey firm Respondi recruited respondents from the population of eligible voters to whom the survey was administered online. The survey was programmed in Qualtrics Survey Software. We used quotas for age, gender, and state to avoid any lack of balance of the sample with regard to these covariates. The Supplementary Information provides detailed information about the survey translation and descriptive statistics for the sample. Informed consent was obtained from each participant at the beginning of the survey. The online survey was fielded from 26 March 2020 until 1 April 2020. We excluded 108 respondents from the sample because of speeding, which is defined as a response time less than half of the median response time.

Study design. All respondents participated in both experiments. The priming experiment was conducted first, after respondents had already answered several questions regarding their political attitudes. The framing experiment was the last item of the survey. Between the priming and the framing experiments, the respondents were asked a series of question about their socio-economic characteristics.

Priming experiment. Forced open-response questions were used as treatment. Each respondent was randomly assigned to one of three conditions: (1) a baseline condition; (2) a condition under which respondents had to answer two open-response questions on COVID-19; and (3) a condition under which respondents had to answer two open-response questions on the German constitution (Grundgesetz). Randomization was automated, thus the investigators were blinded to the treatment assignment allocation during the survey administration. For the COVID-19 priming, we asked the following question:

"To slow down the spread of the novel coronavirus (SARS-CoV-2), comprehensive measures have been adopted to reduce social contacts in public places (so-called 'lockdown'). The measures include the closure of schools and day-care centers, sports 
and cultural facilities, restaurants and bars, and a general ban on contact. Speaking personally, in which situation do you feel particularly restricted by the measures?" [open-response; minimum response length: 15 letters]

"Can you also see a positive side to the measures to reduce social contacts?" [open response; no minimum response length]

For the constitutional priming, we asked the following question:

"The constitution contains rules on how a state is structured and who can pass laws. The Grundgesetz is the constitution of the Federal Republic of Germany. Last year the Grundgesetz turned 70 years old. Generally speaking, what do you appreciate about the constitution of the Federal Republic of Germany?" [open-response; minimum response length: 15 letters]

"Are there also things where you wish the constitution would be changed?" [open response; no minimum response length]

The constitutional priming was designed to examine the effectiveness of the COVID-19 prime, since the omnipresence of the pandemic may undermine the COVID-19 prime. Immediately after the open response questions, respondents in the two treatment conditions were prompted to the following slider questions. Respondents on the baseline condition were prompted to these questions directly. For the 'federal vs. state' dimension we ask:

"There are policy areas in which the individual federal states decide on regulations and other policy areas in which the Federal Republic decides. How do you see this? How should the responsibilities be divided between the federal government and the states? $0=$ More responsibilities for the federal government; $50=$ It should remain as it is; $100=$ More responsibilities for the federal states" [the slider had the value 50 as starting value]

For the 'government vs. parliament' dimension we ask:

"In order to issue generally valid and binding regulations, governments (state and federal governments) depend on the approval of the parliaments (Landtag, Bundestag). How do you see this? How should the legislative competence be distributed between government and parliament? $0=$ More powers for the government; $50=$ It should remain 
as it is; $100=$ More powers for the Parliament" [the slider had the value 50 as starting value]

Framing experiment. Each respondent was randomly assigned to one of three conditions: (1) a baseline condition; (2) an economy trade-off condition; and (3) a civil rights trade-off condition. Randomization was automated, thus the investigators were blinded to the treatment assignment allocation during the survey administration. For the baseline condition, we asked the following question:

"Finally, due to the current situation, we would like to ask you about the spread of the novel coronavirus (SARS-CoV-2) and the political measures to contain it. What do you think about the following statement? The state must take all measures to minimize the number of deaths caused by the novel coronavirus." [scale from 1-11 with radio-buttons; scale endpoints: 1 = "do not agree at all", 11 = "fully agree"]

In the economy trade-off condition, we altered the last statement as follows:

"The state must take all measures to minimize the number of deaths caused by the novel coronavirus, even if these measures cause a long-term loss of prosperity through insolvencies, unemployment and public debt."

In the civil rights trade-off condition, we altered the last statement as follows:

"The state must take all measures to minimize the number of deaths caused by the novel coronavirus, even if these measures represent a long-term restriction of civil liberties (e.g. freedom of assembly and movement)." 
Table S1. Definition of variables. This table describes other respondent attitudes and characteristics measured in the survey.

\begin{tabular}{|l|l|}
\hline Variable & Definition \\
\hline Age & Self-reported age \\
\hline Gender & Self-reported gender (female, male) \\
\hline Education & Self-reported highest level of graduation \\
\hline State & $\begin{array}{l}\text { German Federal States (Länder); Baden-Württemberg, Bavaria, } \\
\text { Berlin, Brandenburg, Bremen, Hamburg, Hesse, Mecklenburg- } \\
\text { Vorpommern, Lower Saxony, North Rhine-Westphalia, Rhineland- } \\
\text { Palatinate, Saarland, Saxony, Saxony-Anhalt, Schleswig-Holstein, } \\
\text { Thuringia }\end{array}$ \\
\hline $\begin{array}{l}\text { Logged number of } \\
\text { infected inhabitants in } \\
\text { a respondent's local } \\
\text { district (Landkreis) } \\
\text { per 100,000 } \\
\text { inhabitants }\end{array}$ & $\begin{array}{l}\text { The data are the "Case Figures in Germany" of the Robert Koch } \\
\text { Institute (RKI) and are available under the Open Data License } \\
\text { Germany - Attribution - Version 2.0. Sources: Robert Koch Institute } \\
\text { (RKI), dl-en/by-2-0. We used time series case figures for the } \\
\text { counties (Landkreise). https://npgeo-corona-npgeo- } \\
\text { Lefhub.arcgis.com/datasets/917fc37a709542548cc3be077a786c17_0 }\end{array}$ \\
\hline $\begin{array}{l}\text { Left-Right-Scale } \\
\text { about 'left' and 'right'. If you use this scale from 1 ("far left") to 11 } \\
\text { ("far right"), where would you place yourself on the scale?" }\end{array}$ \\
\hline
\end{tabular}


Table S2. Summary statistics for categorical variables.

\begin{tabular}{|l|r|r|}
\hline & $\mathrm{N}$ & $\%$ \\
\hline Sex & & 597 \\
\hline Male & 595 & 50.08 \\
\hline Female & & 49.92 \\
\hline Education & 10 & 0.84 \\
\hline In school & 2 & 0.17 \\
\hline Left school without certificate & 101 & 8.47 \\
\hline Primary school leaving certificate (Hauptschulabschluss) & 365 & 30.62 \\
\hline Secondary school leaving certificate (Realschulabschluss) & 146 & 12.25 \\
\hline Advanced technical college entrance qualification (Fachabitur) & 568 & 47.65 \\
\hline University-entrance diploma (Abitur) & & \\
\hline State & 152 & 12.75 \\
\hline Baden-Württemberg & 48 & 4.03 \\
\hline Berlin & 175 & 14.68 \\
\hline Bayern & 38 & 3.19 \\
\hline Brandenburg & 13 & 1.09 \\
\hline Bremen & 26 & 2.18 \\
\hline Hamburg & 93 & 7.8 \\
\hline Hessen & 24 & 2.01 \\
\hline Mecklenburg-Vorpommern & 123 & 10.32 \\
\hline Niedersachsen & 263 & 22.06 \\
\hline Nordrhein-Westfalen & 62 & 5.2 \\
\hline Rheinland-Pfalz & 11 & 0.92 \\
\hline Saarland & 57 & 4.78 \\
\hline Sachsen & 35 & 2.94 \\
\hline Sachsen-Anhalt & 35 & 2.94 \\
\hline Schleswig-Holstein & 37 & 3.1 \\
\hline Thüringen & & \\
\hline & & \\
\hline
\end{tabular}


Figure S1. Summary statistics for continuous variables.

a) Respondents' age

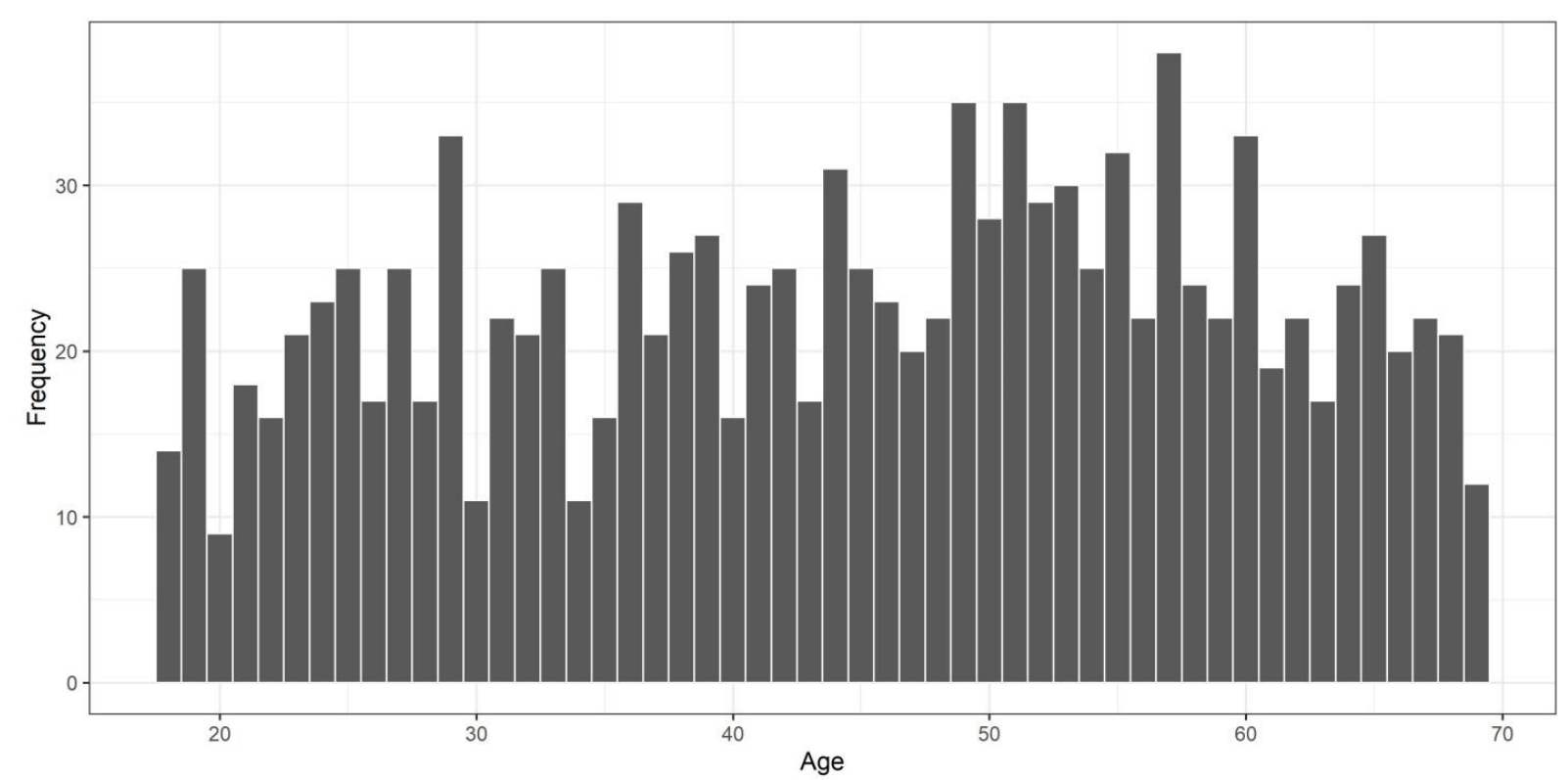

b) Number of infected inhabitants per 100,000 inhabitants in respondents' local district ('Landkreis')

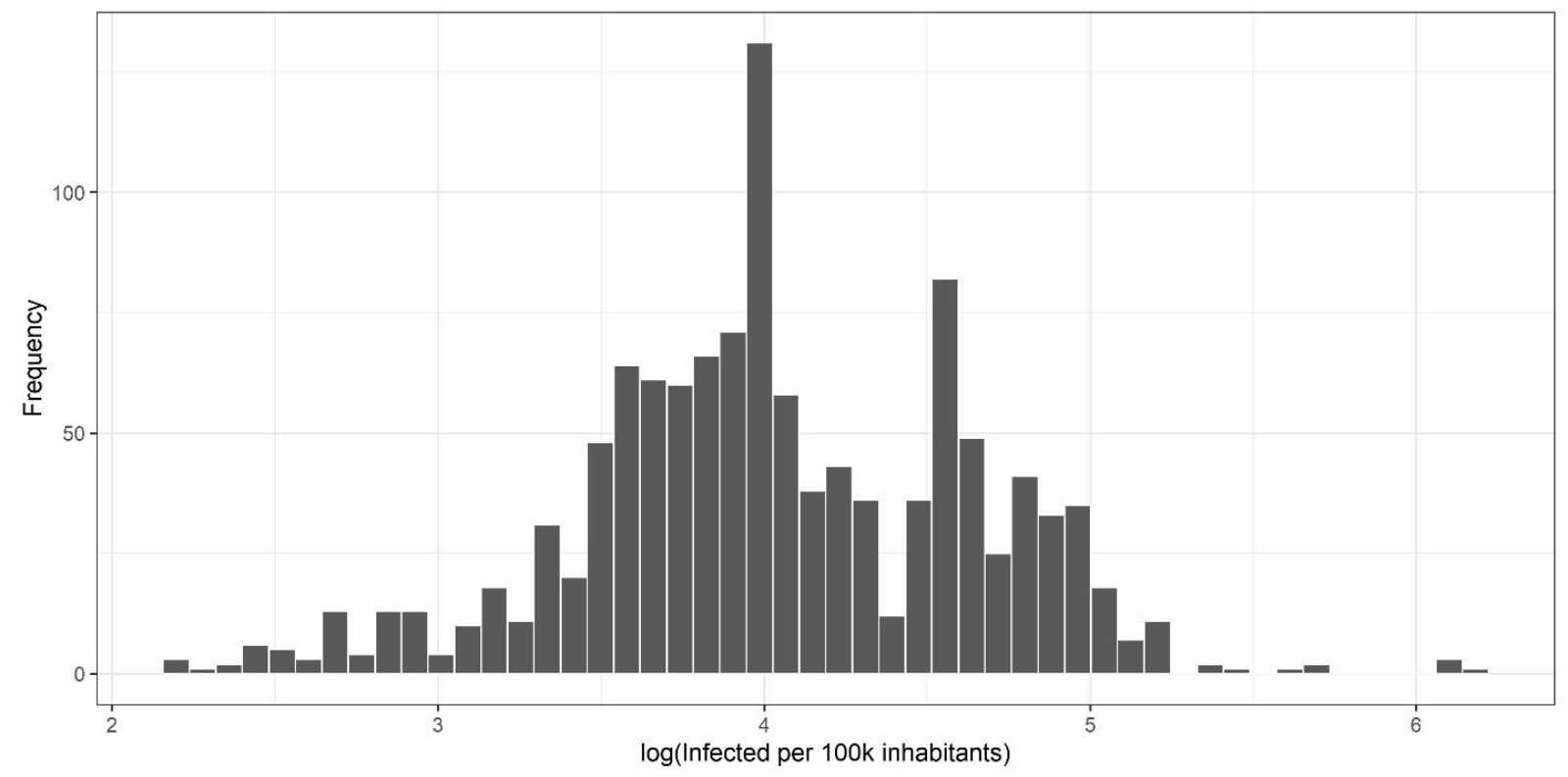


c) Respondents' left-right self-placement

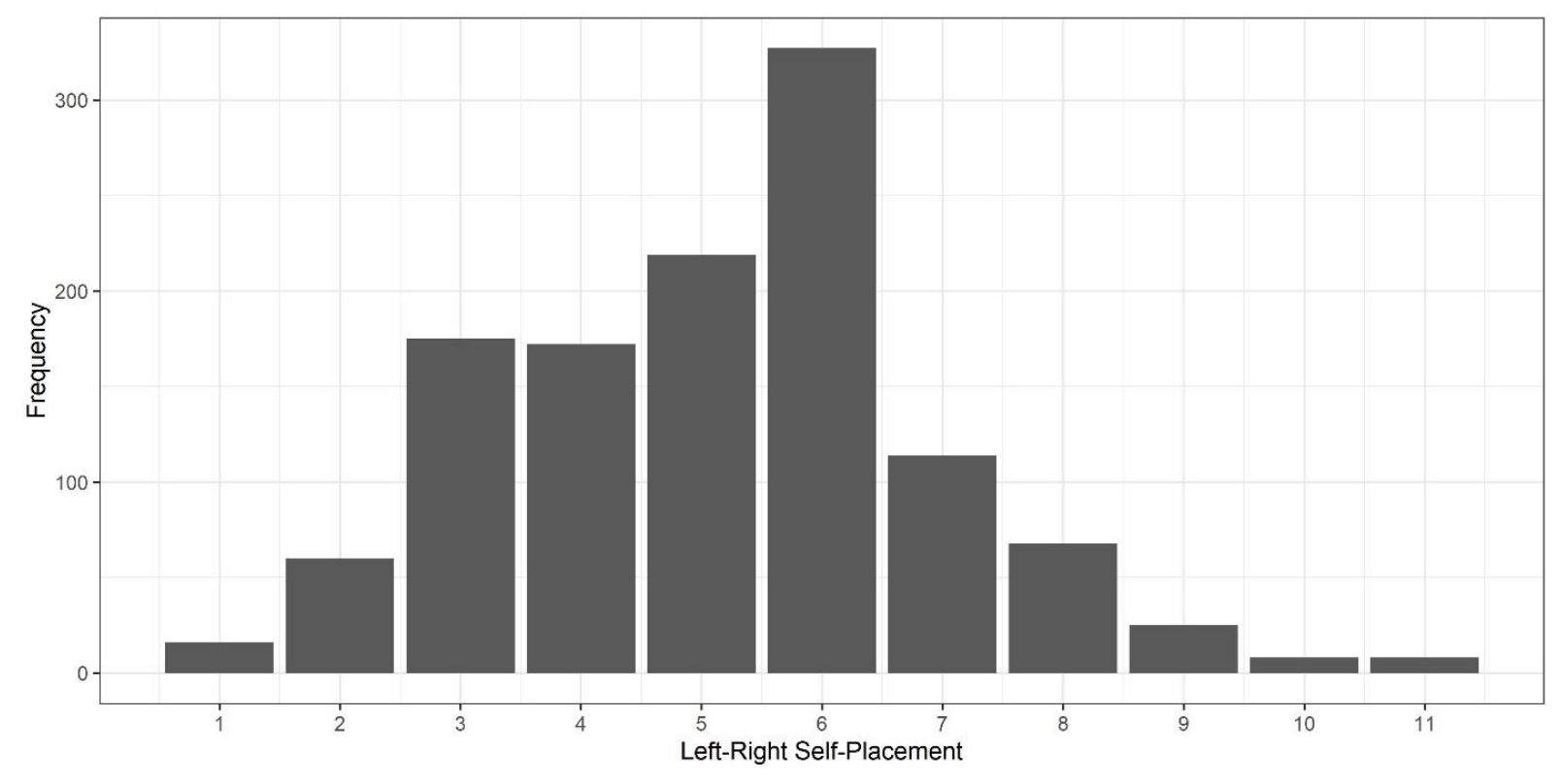


Table S3. Balance Check for Priming Experiment. Table shows covariate means (with standard errors) for respondents randomly assigned to each of the three survey treatment conditions, with p-values from F-Test.

\begin{tabular}{|l|c|c|c|c|}
\hline Variable & Baseline & Corona Prime & $\begin{array}{c}\text { Constitution } \\
\text { Prime }\end{array}$ & $\begin{array}{c}\text { p-value } \\
\text { (F-Test) }\end{array}$ \\
\hline $\mathrm{N}$ & 389 & 404 & 399 & \\
\hline Female & $\begin{array}{c}0.514 \\
(0.025)\end{array}$ & $\begin{array}{c}0.507 \\
(0.025)\end{array}$ & $\begin{array}{c}0.481 \\
(0.025)\end{array}$ & 0.619 \\
\hline Age & $\begin{array}{c}44.4 \\
(0.72)\end{array}$ & $\begin{array}{c}45.1 \\
(0.71)\end{array}$ & $\begin{array}{c}44.4 \\
(0.71)\end{array}$ & 0.724 \\
\hline $\log ($ Infected/100k) & $\begin{array}{c}4.01 \\
(0.031)\end{array}$ & $\begin{array}{c}4.02 \\
(0.03)\end{array}$ & $\begin{array}{c}4.07 \\
(0.03)\end{array}$ & 0.257 \\
\hline Left-Right & $\begin{array}{c}5.01 \\
(0.092)\end{array}$ & $\begin{array}{c}5.23 \\
(0.09)\end{array}$ & $\begin{array}{c}5.22 \\
(0.091)\end{array}$ & 0.161 \\
\hline
\end{tabular}

Table S4. Balance Check for Framing Experiment. Table shows covariate means (with standard errors) for respondents randomly assigned to each of the three survey treatment conditions, with p-values from F-Test.

\begin{tabular}{|l|c|c|c|c|}
\hline Variable & Baseline & Corona Prime & $\begin{array}{c}\text { Constitution } \\
\text { Prime }\end{array}$ & $\begin{array}{c}\text { p-value } \\
\text { (F-Test) }\end{array}$ \\
\hline $\mathrm{N}$ & 405 & 383 & 404 & \\
\hline Female & $\begin{array}{c}.479 \\
(0.025)\end{array}$ & $\begin{array}{c}.525 \\
(.026)\end{array}$ & $\begin{array}{c}0.5 \\
(0.025)\end{array}$ & 0.438 \\
\hline Age & $\begin{array}{c}44.4 \\
(0.71)\end{array}$ & $\begin{array}{c}45.7 \\
(0.72)\end{array}$ & $\begin{array}{c}43.9 \\
(0.71)\end{array}$ & 0.179 \\
\hline $\log ($ Infected/100k) & $\begin{array}{c}4.05 \\
(0.03)\end{array}$ & $\begin{array}{c}4.01 \\
(0.03)\end{array}$ & $\begin{array}{c}4.04 \\
(0.03)\end{array}$ & 0.624 \\
\hline Left-Right & $\begin{array}{c}5.22 \\
(0.09)\end{array}$ & $\begin{array}{c}5.11 \\
(0.09)\end{array}$ & $\begin{array}{c}5.12 \\
(0.09)\end{array}$ & 0.630 \\
\hline
\end{tabular}


Table S5. Effect of framing and priming treatments on respondents' preferences for maximalist public health approach during the COVID-19 pandemic. The priming treatment has no effect on the framing experiment outcome and does not moderate the framing treatments.

\begin{tabular}{lcc}
\hline & $(1)$ & $(2)$ \\
\hline Economy Frame & $-1.674^{* * * *}$ & $-1.507^{* * *}$ \\
Freedom Frame & $(0.172)$ & $(0.280)$ \\
& $-0.520^{* * *}$ & $-0.688^{*}$ \\
Corona Prime & $(0.161)$ & $(0.279)$ \\
Constitution Prime & -0.125 & -0.0778 \\
& $(0.176)$ & $(0.237)$ \\
Economy Frame * Corona Prime & -0.167 & -0.195 \\
& $(0.168)$ & $(0.250)$ \\
Economy Frame * Constitution Prime & & -0.324 \\
& & $(0.434)$ \\
Freedom Frame * Corona Prime & & -0.193 \\
Freedom Frame * Constitution Prime & & $(0.400)$ \\
Constant & & 0.183 \\
& & $(0.391)$ \\
Observations & & 0.294 \\
Adjusted ${ }^{2}$ & $9.610^{* * *}$ & $(0.398)$ \\
\hline
\end{tabular}

Note: OLS regression estimates are shown. Robust standard errors are in parentheses. ${ }^{*}=\mathrm{p}<$ $0.05, * * \mathrm{p}<0.01, * * * \mathrm{p}<0.001$. 
Figure S2. Geo-location of respondents in local districts (Landkreise)

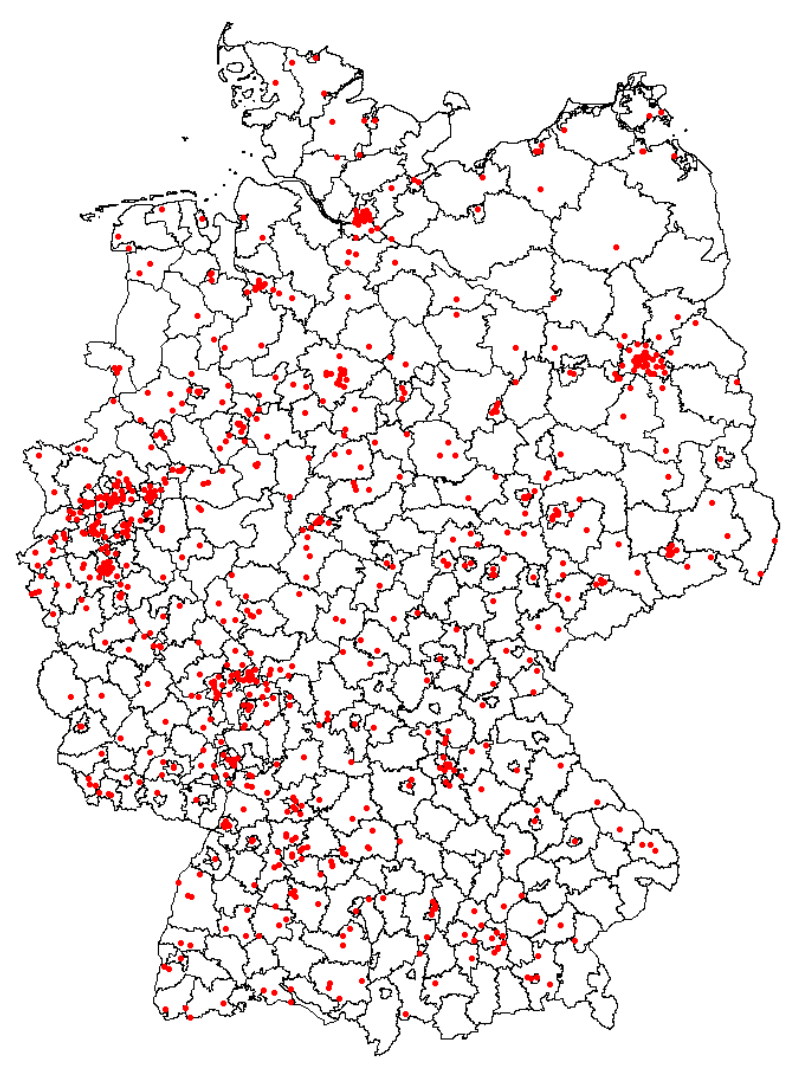


Figure S3a/b. Corona Prime conditioned by age a) Corona Prime on Federal vs. State by Age

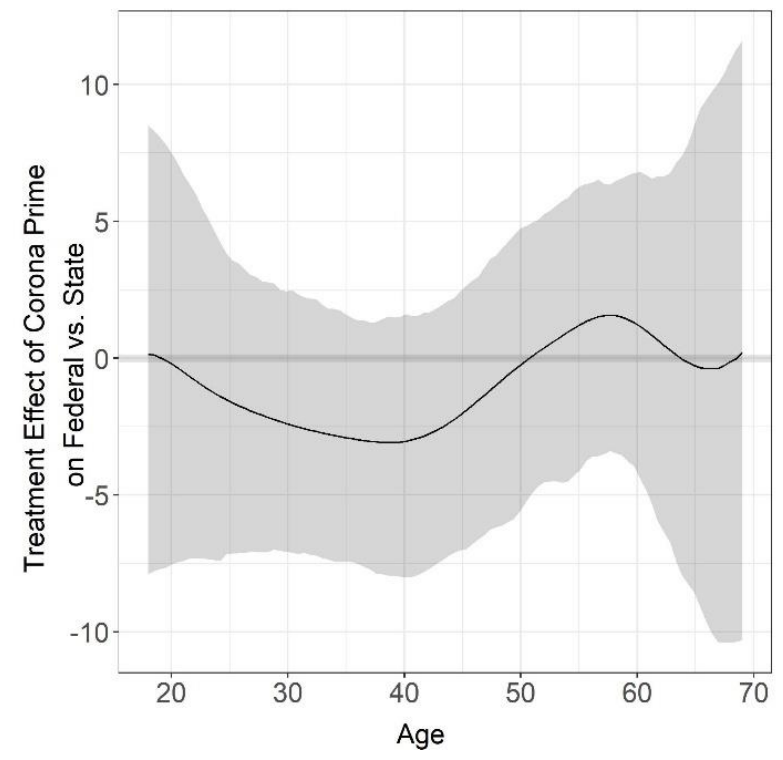

b) Corona Prime on Government vs. Parliament by Age

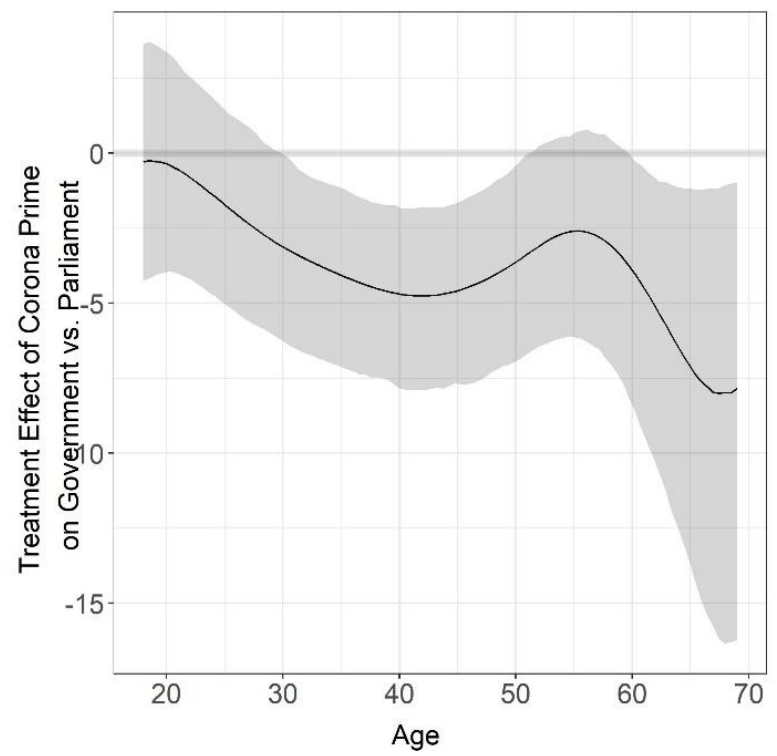

Figure S4a/b. Constitutional Prime conditioned by age

a) Constitution Prime on Federal vs. State by Age

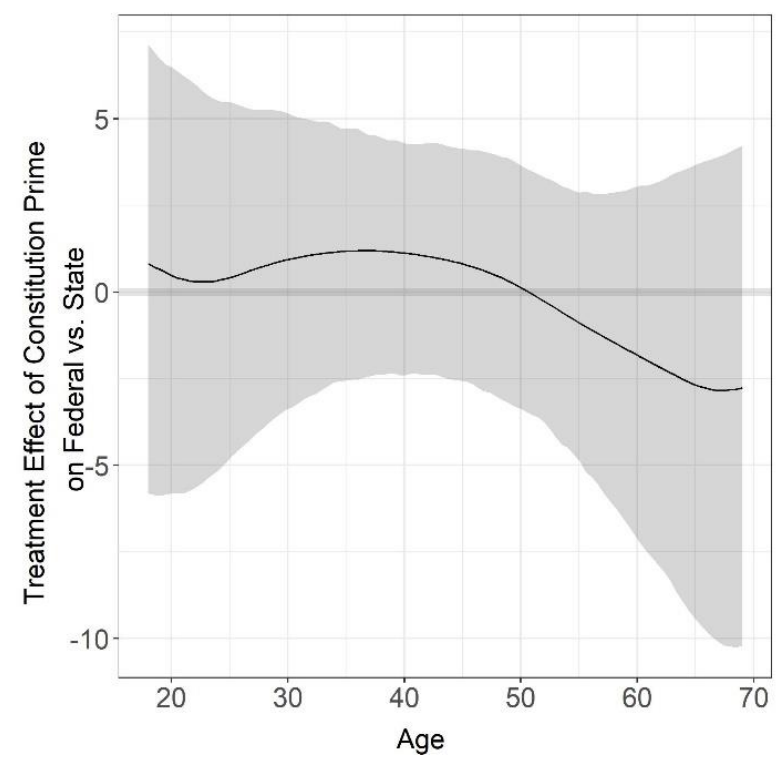

b) Constitution Prime on Government vs. Parliament by Age

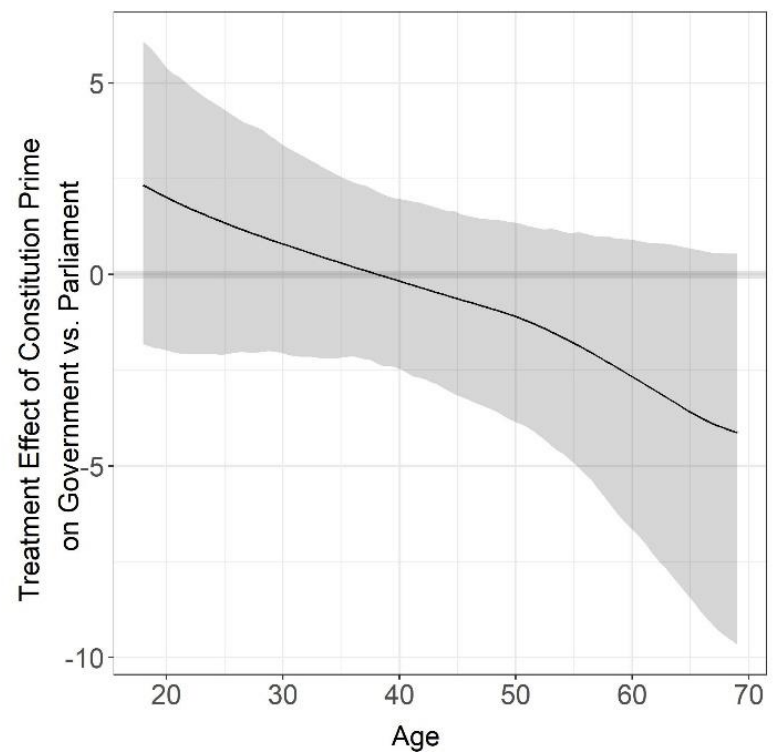


Figure S5a/b. Corona Prime conditioned by number of infected $(\log )$
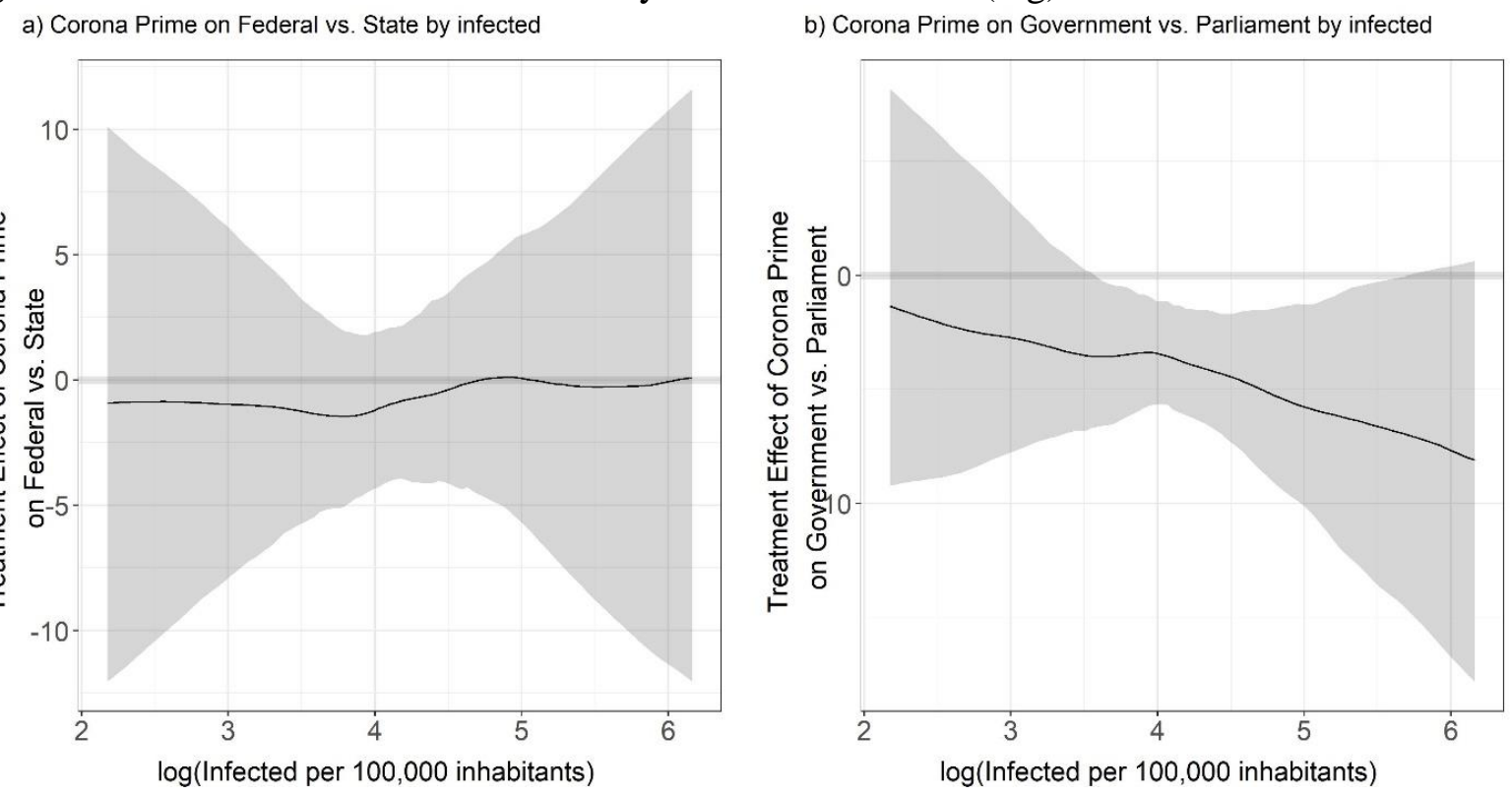

Figure S6a/b. Constitution Prime conditioned by number of infected (log)

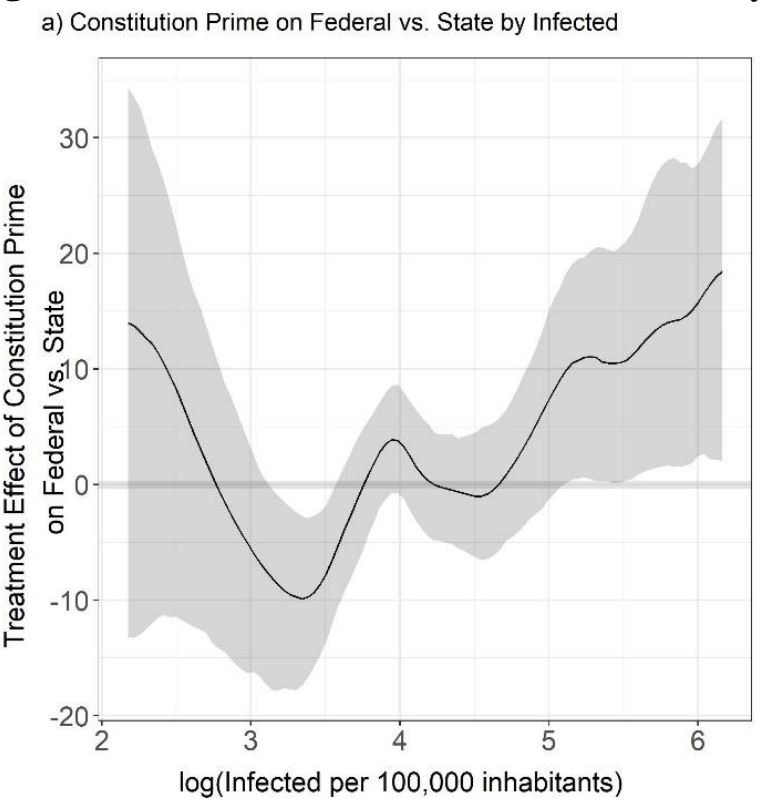

b) Constitution Prime on Government vs. Parliament by Infected

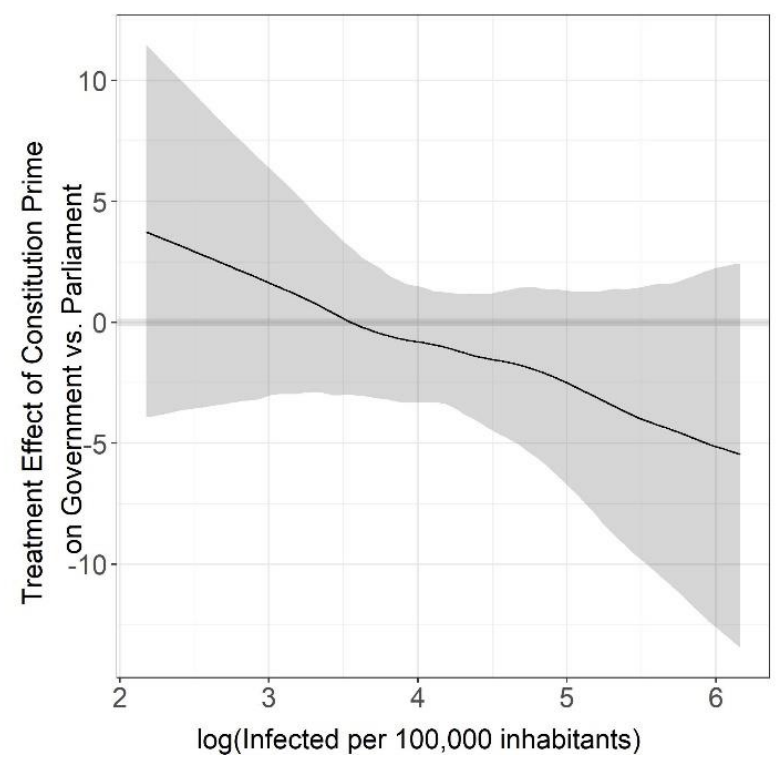


Figure S7a/b. Framing effect conditioned by left-right placement

a) Economy Frame by Left-Right Self-Placement

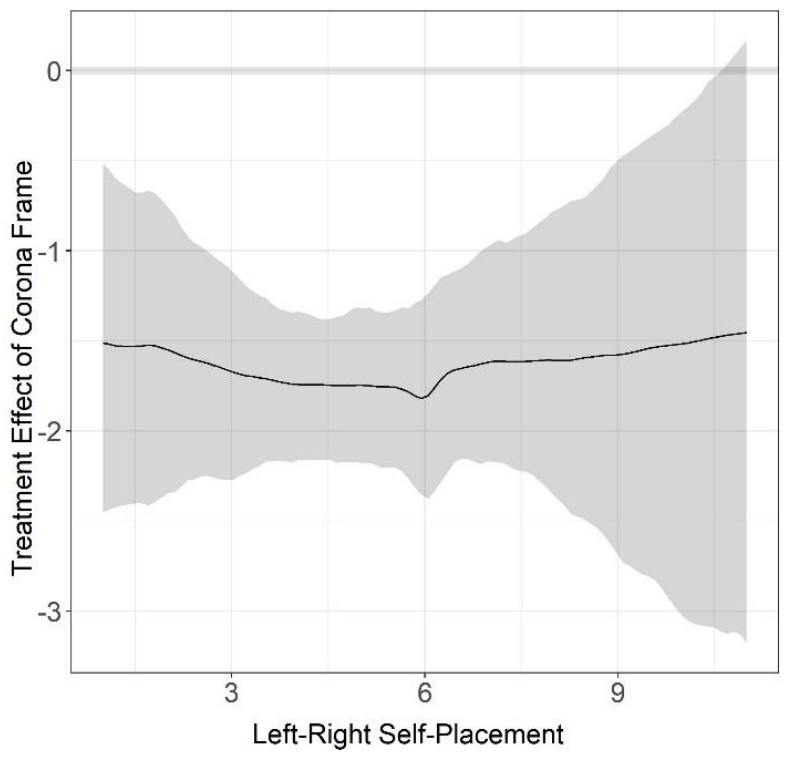

b) Freedom Frame by Left-Right Self-Placement

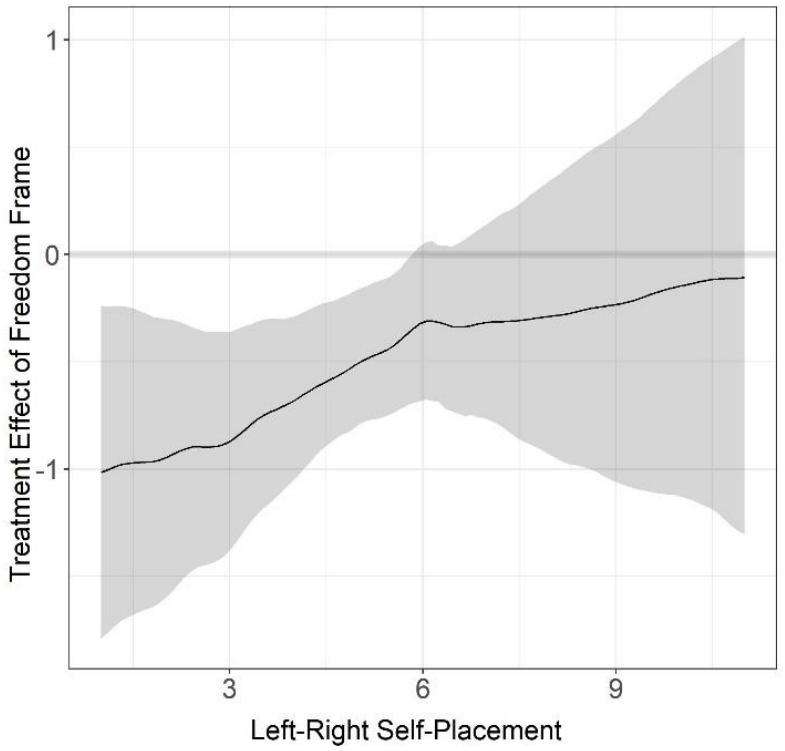

